\title{
Ghrelin therapy mitigates bone marrow injury and splenocytopenia by sustaining circulating G-CSF and KC increases after irradiation combined with wound
}

\author{
Juliann G. Kiang ${ }^{1,2,3^{*}}$, Marsha N. Anderson ${ }^{1}$ and Joan T. Smith ${ }^{1}$
}

\begin{abstract}
Background: Radiation injury combined wound $(\mathrm{Cl})$ enhances acute radiation syndrome and subsequently mortality as compared to radiation injury alone (RI). We previously reported that ghrelin (a 28-amino-acid-peptide secreted from the stomach) treatment significantly increased a 30-day survival, mitigated hematopoietic death, circulating white blood cell (WBC) depletion and splenocytopenia and accelerated skin-wound healing on day 30 after $\mathrm{Cl}$. Herein, we aimed to study the ghrelin efficacy at early time points after $\mathrm{Cl}$.

Methods: B6D2F1/J female mice were exposed to ${ }^{60} \mathrm{Co}-\gamma$-photon radiation at $9.5 \mathrm{~Gy}\left(\mathrm{LD}_{50 / 30}\right)$ followed by a $15 \%$ total-body-surface-area skin wound. Several endpoints were measured at 4-5 h, days 1, 3, 7 and 15.

Results: Histological analysis of sternums on day 15 showed that $\mathrm{Cl}$ induced more adipocytes and less megakaryocytes than RI. Bone marrow cell counts from femurs also indicated $\mathrm{Cl}$ resulted in lower bone marrow cell counts on days 1, 7 and 15 than RI. Ghrelin treatment mitigated these Cl-induced adverse effects. RI and Cl decreased WBCs within $4-5 \mathrm{~h}$ and continued to decrease to day 15 . Ghrelin treatment mitigated decreases in $\mathrm{Cl}$ mice, mainly from all types of WBCs, but not RBCs, hemoglobin levels and hematocrit values. Ghrelin mitigated the Cl-induced thrombocytopenia and splenocytopenia. Cl increased granulocyte-colony stimulating factor (G-CSF) and keratinocyte chemoattractant (KC) in blood and bone marrow. Ghrelin therapy was able to enhance and sustain the increases in serum on day 15, probably contributed by spleen and ileum, suggesting the correlation between G-CSF and KC increases and the neutropenia mitigation. Activated caspase-3 levels in bone marrow cells were significantly mitigated by ghrelin therapy on days 3 and 15.
\end{abstract}

Conclusions: Our novel results are the first to suggest that ghrelin therapy effectively decreases hematopoietic death and splenocytopenia by sustaining circulating G-CSF and KC increases after Cl. These results demonstrate efficacy of ghrelin as a radio-mitigator/therapy agent for $\mathrm{Cl}$.

Keywords: Ionizing radiation, Skin wound, Ghrelin, Bone marrow, WBC, RBC, Spleen, G-CSF, KC, Caspase, Apoptosis

\section{Background}

Radiation exposure accidents and detonation in the past have shown that irradiated victims experienced radiation injury (RI) also often concurrently received other

\footnotetext{
*Correspondence: juliann.kiang@usuhs.edu

2 Department of Pharmacology and Molecular Therapeutics, Uniformed Services University of the Health Sciences, Bethesda, MD 20814, USA Full list of author information is available at the end of the article
}

trauma such as wounds, burns, blast or hemorrhage as well, namely combined injury (CI). CI was observed after Atomic bombing, Hiroshima and Nagasaki, Japan and at the Chernobyl reactor meltdown with $60-70 \%$ of victims $[1,2]$ and $10 \%$ of victims [3], respectively received thermal burns concurrent with radiation injury. Burns, wounds and infections usually increase mortality after otherwise non-lethal radiation dose observed in animal models of CI including mice [4-12], rats [13-15], guinea 
pigs [16], dogs [17, 18] and swine [19]. CI also delays wound closure times from normally 14 days after wounding without radiation to more than 30 days after irradiation $[4,7,8,20]$.

CI results in much severe outcomes than RI. Accelerated body-weight loss, amplified cytokine and chemokine imbalance, systemic bacterial infection [4], enhanced leukocytopenia, thrombocytopenia and erythrocytopenia [5, $7,8]$, acute myelosuppression [4], immune system inhibition, fluid imbalance, macro- and microcirculation failure, massive cellular damage and disruption of vital organ functions are observed and subsequently lead to multiple organ dysfunction (MOD) and multiple organ failure (MOF). As a result, death after CI occurs [16, 21, 22]. In our mouse model of RI and CI, the median lethal dose to cause $50 \%$ population dead over 30 days $\left(\mathrm{LD}_{50 / 30}\right)$ for $\mathrm{RI}$ is around $9.65 \mathrm{~Gy}$, whereas radiation-wound $\mathrm{CI}(\mathrm{R}-\mathrm{W} \mathrm{CI})$ is around $8.95 \mathrm{~Gy}$. The dose modifying factor (DMF) is 1.08 [4]. It is speculated that intervention of CI-induced aggravation of body-weight loss, cytokine imbalance or bacterial sepsis should improve the survival. Drugs or biologics such as pegylated G-CSF [7], ciprofloxacin [8, 20], mesenchymal stem cells [23], and ghrelin [24], prove to be effective to increase 30-day survival. However, their underlying mechanisms are not elucidated yet. Ghrelin effects at early time points after $\mathrm{CI}$ in bone marrow histopathology, circulating blood cells, cytokines and chemokines, and apoptosis were investigated.

Among of them, ghrelin was studied. Ghrelin is a hormone that is a hunger-stimulating peptide containing 28 amino acids [25]. It is produced mainly by P/D1 cells lining the fundus of the human stomach and epsilon cells of the pancreas [26]. Ghrelin levels increase before meals and decrease after meals. It's counterpart hormone is leptin produced by adipose tissue [27].

Ghrelin potently stimulates growth hormone from the anterior pituitary gland [25]. Ghrelin activates the endothelial isoform of nitric oxide synthase (eNOS) in a pathway [28] that depends on PI3K/Akt/eNOS/NO signal pathway $[29,30]$. Ghrelin binds on growth hormone secretagogue receptors that is coupled to G-protein [25].

It is reported that human ghrelin decreased organ injury and increased survival by $30 \%$ above the vehicletreated mice after RI combined with severe sepsis in rats [14]. Kiang et al. [24] reported that ghrelin therapy was efficacious in a mouse model of radiation combined with wound or burn by increasing survival, body weight, wound healing, bone marrow cell counts, neutrophil recovery and platelet recovery on day 30 post $\mathrm{CI}$ as well as inhibiting brain hemorrhage [31]. Ghrelin blocks NF- $\mathrm{kB}$ activation, decreased TNF- $\alpha$ and IL- 6 concentrations in lung of septic rats and inhibited nucleotide-binding oligomerization domain-containing protein 2 [NOD2, also known as caspase recruitment domain-containing protein 15 (CARD15) or inflammatory bowel disease protein 1 (IBD1)] [32]. NOD2 is important for apoptosis and the NF- $\mathrm{kB}$ activation pathways [33]. Ghrelin inhibits IкB and increases Th1 cytokine and IL-17 secretion in primary $\mathrm{T}$ cells [34]. Because RI and CI induce increased production of inflammatory cytokines and chemokines [4-6], it is thought that interventions which would early mitigate inflammatory responses could likely improve survival after CI. We, therefore, wanted to elucidate the dynamic changes in hematopoietic cell death and its related signaling molecules such as granulocyte-colony stimulating factor (G-CSF) and keratinocyte chemattractant (KC) at early time points. This report provides evidence from an experimental CI animal model, which was designed to demonstrate a kinetic change in hematopoiesis in circulating blood cells correlating with circulating G-CSF and $\mathrm{KC}$ and bone marrow G-CSF, KC, and caspase-3 activity.

\section{Methods}

\section{Experimental design}

B6D2F1/J female mice were randomly divided into 8 groups: (1) sham vehicle, (2) wound vehicle, (3) RI vehicle, (4) CI vehicle, (5) sham ghrelin, (6) wound ghrelin, (7) RI ghrelin, and (8) CI ghrelin. Groups 2, 4, 6 and 8 received topical gentamicin cream; groups 1-8 were administered with oral levofloxacin. $\mathrm{N}=6$ mice per group per time point. Hematological analysis, spleen weights, splenocyte counts, sternum histopathology and femur bone marrow cell counts of surviving animals were performed at each specified time point. The AFRRI Institutional Animal Care and Use Committee reviewed and approved all animal procedures. Euthanasia was carried out in accordance with the recommendations and guidance of the American Veterinary Medical Association $[35,36]$.

\section{Animals}

B6D2F1/J female mice (The Jackson Laboratory, Bar Harbor, ME) were maintained in a facility accredited by the Association for Assessment and Accreditation of Laboratory Animal Care International in plastic microisolator cages on hardwood chip bedding. Commercial rodent chow and acidified tap water were provided ad libitum at 12-20 weeks of age. Animal holding rooms were maintained at $21 \pm 1{ }^{\circ} \mathrm{C}$ with $50 \pm 10 \%$ relative humidity using at least 10 changes/h of $100 \%$ conditioned fresh air. A 12-h 0600 (light) to 1800 (dark) full-spectrum lighting cycle was used.

\section{Gamma irradiation}

Mice were given $9.5 \mathrm{~Gy}\left[\mathrm{LD}_{50 / 30}\right.$, bilateral, see Ref. 5] whole-body bilateral ${ }^{60} \mathrm{Co} \gamma$-photon radiation, delivered 
at a dose rate of $0.4 \mathrm{~Gy} / \mathrm{min}$, while held in vertically stacked, ventilated, four-compartment, acrylic plastic boxes that provided electron equilibrium during irradiation. Empty compartments within the boxes were filled with 3-inch-long $\times 1$-inch-diameter acrylic phantoms to ensure uniform electron scattering. The mapping of the radiation field was performed with alanine/EPR dosimetry [37] using standard alanine calibration sets from US National Institute of Standards and Technology and National Physical Laboratory of the United Kingdom. The mapping provided dose rates to water measured by alanine pellets placed in the hollowed core of the acrylic phantoms in each compartment of the mouse rack on the day of the mapping. The field was uniform within $\pm 1.8 \%$ over all the 120 compartments. The exposure time for each irradiation was determined from the mapping data; corrections for the ${ }^{60} \mathrm{Co}$ decay and the small difference in the mass energy absorption coefficients for water and soft tissue were applied. The accuracy of the actual dose delivery was verified with an ionization chamber adjacent to the mouse rack, which had been calibrated in terms of dose to the mid-line soft tissue of mice.

\section{Skin injury}

Skin surface injuries were performed on the shaved dorsal surface of mice. Animals receiving skin wounds were anesthetized by isoflurane inhalation. A 15\% total bodysurface-area skin wound was performed within $1 \mathrm{~h}$ after irradiation [4]. All mice subjected to the skin injury were given $0.5 \mathrm{~mL}$ sterile $0.9 \% \mathrm{NaCl}$ intraperitoneally (i.p.), which contained $150 \mathrm{mg} / \mathrm{kg}$ of acetaminophen (AmerisourceBergen, Glen Alen, Virginia), immediately after skin injury to alleviate pain. The sham group received the same handling procedure except administration of $0.5 \mathrm{ml}$ sterile $0.9 \% \mathrm{NaCl}$ containing $150 \mathrm{mg} / \mathrm{kg}$ of acetaminophen.

\section{Ghrelin}

Ghrelin was purchased from Phoenix Pharmaceutical (Burlingame, CA). Three doses of $113 \mu \mathrm{g} / \mathrm{kg}$ were administered by lateral tail-vein injections [14] in a volume of $0.2 \mathrm{ml} \mathrm{24,} 48$ and $72 \mathrm{~h}$ after RI or CI. The vehicle given to control mice was sterile $0.9 \%$ sodium chloride solution for injection, USP.

\section{Antimicrobial agents}

Gentamicin sulfate cream, 0.1\% (generic, E. Fougera and Co., Melville, N.Y., NDC 0168-007-15), was applied daily for 10 days to the skin injuries on days 1-10. Levofloxacin (LVX), (generic, Aurobindo Pharma, Ltd., Mahaboob Nagar, India, NDC 65862-537-50), $100 \mathrm{mg} / \mathrm{kg}$ in $0.2 \mathrm{ml} /$ mouse, was administered p.o. daily for 14 days on days 3-16. Briefly, a 500-mg tablet was crushed by mortar and pestle. The LVX in the powder was dissolved in a volume of sterile water approximately one-third the total volume required to prepare the concentration needed for the average body mass of the mice to be treated. The mortar was rinsed with the remaining two-thirds volume of sterile water. The combined suspension was centrifuged to remove the particulate filler and the supernatant solution was passed through a $0.45-\mu \mathrm{m}$ membrane filter into a sterile amber bottle, which was sealed with a sterile rubber stopper and stored at $4-8{ }^{\circ} \mathrm{C}$ [7].

\section{Assessment of blood cell profile in peripheral blood}

Blood samples were collected in EDTA tubes on 4-5 h, days $1,3,7$, and 15 after $\mathrm{RI}$ or $\mathrm{CI}(\mathrm{N}=6$ mice per group per time point) and assessed with the ADVIA 2120 Hematology System (Siemens, Deerfield, IL). Differential analysis was conducted using the peroxidase method and the light scattering techniques recommended by the manufacturer.

\section{Measurements of spleen weights and splenocytes}

Spleens were collected from each euthanized mouse on 4-5 h, days $1,3,7$, and 15 after RI or $\mathrm{CI}(\mathrm{N}=6$ mice per group per time point). Each specimen was weighed, placed in a plastic bag with $10 \mathrm{ml}$ of $1 \times$ Hank's Balanced Salt Solution (Invitrogen, Grand Island, NY) homogenized using Seward Stomacher ${ }^{\circledR} 80$ (Thermo Scientific), and poured through a $70 \mathrm{~mm}$ cell strainer (BD Falcon, Bedford, MA). The fluid with Splenocytes was then centrifuged at $800 \times g$ (Sorvall Legend XTR Centrifuge, Thermo Scientific) for $10 \mathrm{~min}$. The pellet was resuspended in $10 \mathrm{~mL} 1 \times$ ACK lysis buffer (Invitrogen) for $10 \mathrm{~min}$ at $37^{\circ} \mathrm{C}$ to lyse RBCs, mixed by vortexing, and then centrifuged at $800 \times g$. Splenocytes were collected, resuspended in $10 \mathrm{~mL} 1 \times$ phosphate-buffered saline (PBS), placed in Countess ${ }^{\mathrm{TM}}$ cell-counting-chamber slides (Invitrogen, Eugene, Oregon) and counted using the Countess automated cell counter (Invitrogen).

\section{Measurements of bone marrow cells}

Bone marrow cells from femurs were collected on $4-5 \mathrm{~h}$, days $1,3,7$, and 15 after RI or $\mathrm{CI}(\mathrm{N}=6$ mice per group per time point) and washed with $10 \mathrm{ml} 1 \times$ PBS. The cells were then centrifuged at $800 \times g$, re-suspended in $10 \mathrm{ml}$ $1 \times$ PBS buffer, placed in Countess ${ }^{\text {TM }}$ cell-counting-chamber slides (Invitrogen) and counted using the Countess automated cell counter (Invitrogen).

\section{Histopathology assessment}

Sternum specimens were collected from mice on day 15 ( $n=6$ mice per group). Specimens were rinsed in cold saline solution and immediately fixed in $10 \%$ phosphatebuffered formalin. The tissue was then embedded in 
paraffin, sectioned transversely and stained with $H \& E$. The histology slides were scanned using Zeiss Axioscan. Z1. Then, adipocytes and megakaryocytes were counted [4] using Zen 2 software (Zeiss Company, Thornwood, $\mathrm{NY})$.

\section{Measurement of G-CSF and KC}

Blood samples were collected on $4-5 \mathrm{~h}$, days $1,3,7$, and 15 after RI or $\mathrm{CI}$ ( $\mathrm{N}=6$ mice per group per time point) after RI or CI using BD Microtainers (Becton, Dickinson and Company, Franklin Lakes, NJ). Blood samples were placed at room temperature for $30 \mathrm{~min}$ and centrifuged at $9600 \times g$ for $10 \mathrm{~min}$ (Sovall Legend Micro 21 Centrifuge, Thermo Scientific). Then serum was collected. Spleen, ileum, bone marrow, and kidney were minced, blended with beads, homogenized with Bullet Blender Storm 24 (Averill Park, NY), and centrifuged at $9600 \times g$ for $10 \mathrm{~min}$. The supernatants were collected. G-CSF and KC concentrations were measured and analyzed using the Bio-PlexTM Cytokine Assay (Bio-Rad; Hercules, CA) following the manufacturer's directions. Briefly, serum samples and tissue lysates from each animal were diluted fourfold and examined in duplicate. Data were analyzed using the LuminexH 100TM System (Luminex Corp.; Austin, TX) and quantified using MiraiBio MasterPlexH CT and QT Software (Hitachi Software Engineering America Ltd.; San Francisco, CA), and concentrations were expressed in $\mathrm{pg} / \mathrm{mL}$ unless otherwise noted. The cytokines analyzed were IL- $1 \alpha$ IL- $1 \beta$, IL-2, IL-3, IL-4, IL-5, IL-6, IL-9, IL-10, IL-12(p40), IL-12(p70), IL-13, IL-17, eotaxin, G-CSF, GM-CSF, IFN- $\gamma$, KC, MCP1, MIP-1a, MIP-1b, RANTES and TNF-a. Data were expressed as $\mathrm{pg} / \mathrm{mL}$ in serum and $\mathrm{pg} / \mathrm{mg}$ protein in tissues [4]. G-CSF and KC Data were herein reported.

\section{Activated caspase- 3 measurement}

Activated caspase- 3 protein levels were measured using Quantikine ELISA kit according to the manufacturer's protocol (R\&D SYSTEM, Minneapolis, MN).

\section{Statistical analysis}

Parametric data are expressed as the mean \pm sem. For each survival experiment, 6 mice per group were tested on an individual basis. One-way ANOVA, two-way ANOVA, studentized-range test, and Student's t-test were used for comparison of groups, with $5 \%$ as a significant level.

\section{Results}

\section{Ghrelin therapy increases bone marrow cellularity}

It is evident that RI alone induced an increase in adipocyte cell count and CI further induced the increase [38].
Figure 1 shows that the similar outcome was observed. Ghrelin treatment mitigated the increases in both RI and CI mice.

It is also evident that RI alone induced a decrease in megakaryocyte cell counts and CI further enhanced the decrease [38]. Comparable results were obtained herein. Ghrelin therapy significantly recovered the cell count in CI mice but not in RI mice (Fig. 1). Wounding alone with vehicle or ghrelin treatment did not alter the bone marrow morphology.

\section{Ghrelin therapy increases bone marrow cell counts}

To confirm the RI-induced bone marrow cell depletion and the $\mathrm{CI}$ enhancement of bone marrow cell depletion, bone marrow cells were collected from femurs of each animal at different time points post RI and CI treated with vehicle or ghrelin. As shown in Fig. 2, RI significantly reduced bone marrow cell counts from femurs on days 7 and 15. CI enhanced the decreases at 4-5 h and days 1 and 7. Ghrelin treatment significantly recovered bone marrow counts at days 1,7 , and 15 . Wounding alone with vehicle or ghrelin did not alter the counts.

\section{Ghrelin therapy recovers WBCs after wounding and $\mathrm{Cl}$} It is reported that RI decreased WBCs and CI further decreased them [5]. Figure 3 shows that RI-induced decreases in WBCs began within 4-5 h, continued to decrease on day 1 and 3 and remained at the nadir on days 7 and 15 . The decreases were contributed by neutrophils, lymphocytes, monocytes, eosinophils and basophils. CI further decreased the WBCs on day 1 due to the further reduction of neutrophils. Ghrelin therapy recovered WBCs on day 3 . However, data from individual types of WBCs indicated that ghrelin therapy recovered neutrophils and monocytes on days 3 and 15 and lymphocytes, eosinophils and basophils on day 3 . Wounding with ghrelin increased neutrophils and lymphocytes on days 3,7 , and 15 , monocytes on days 7 and 15 , and basophiles on days 3 and 15 .

\section{Ghrelin therapy does not change RBCs after wounding, RI or $\mathrm{Cl}$}

It is known that RI decreased RBCs, hemoglobin and hematocrit and $\mathrm{CI}$ further decreased them [5]. Figure 4 shows that RI-induced decreases in RBCs began on day 3 and continued to decrease on day 15 . CI-induced enhancement was observed on day 15. Ghrelin therapy failed to recover RBCs. Similar observations were obtained with hemoglobin levels and hematocrit readings. Wounding alone with either vehicle or ghrelin did not alter these parameters. 

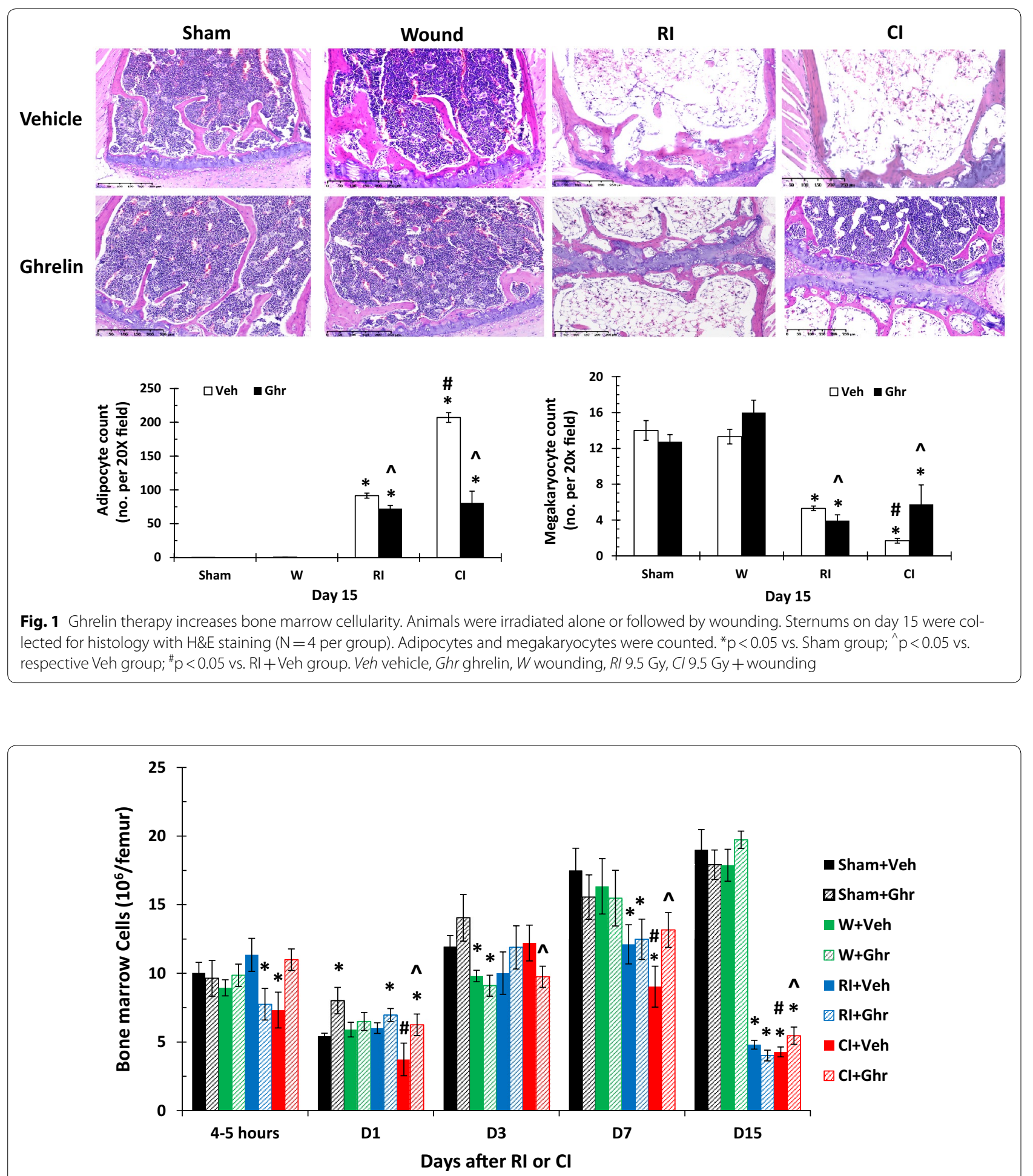

Fig. 2 Ghrelin therapy increases bone marrow cell counts. Animals were irradiated alone or followed by wounding. Femurs on different time points were collected for measuring bone marrow cell counts ( $N=6$ per group). ${ }^{*} p<0.05$ vs. Sham group; ${ }^{\wedge} p<0.05$ vs. respective Veh group; ${ }^{*} p<0.05$ vs. $\mathrm{Rl}+$ Veh group. Veh vehicle, Ghr ghrelin, W wounding, Rl $9.5 \mathrm{~Gy}$, Cl $9.5 \mathrm{~Gy}+$ wounding 


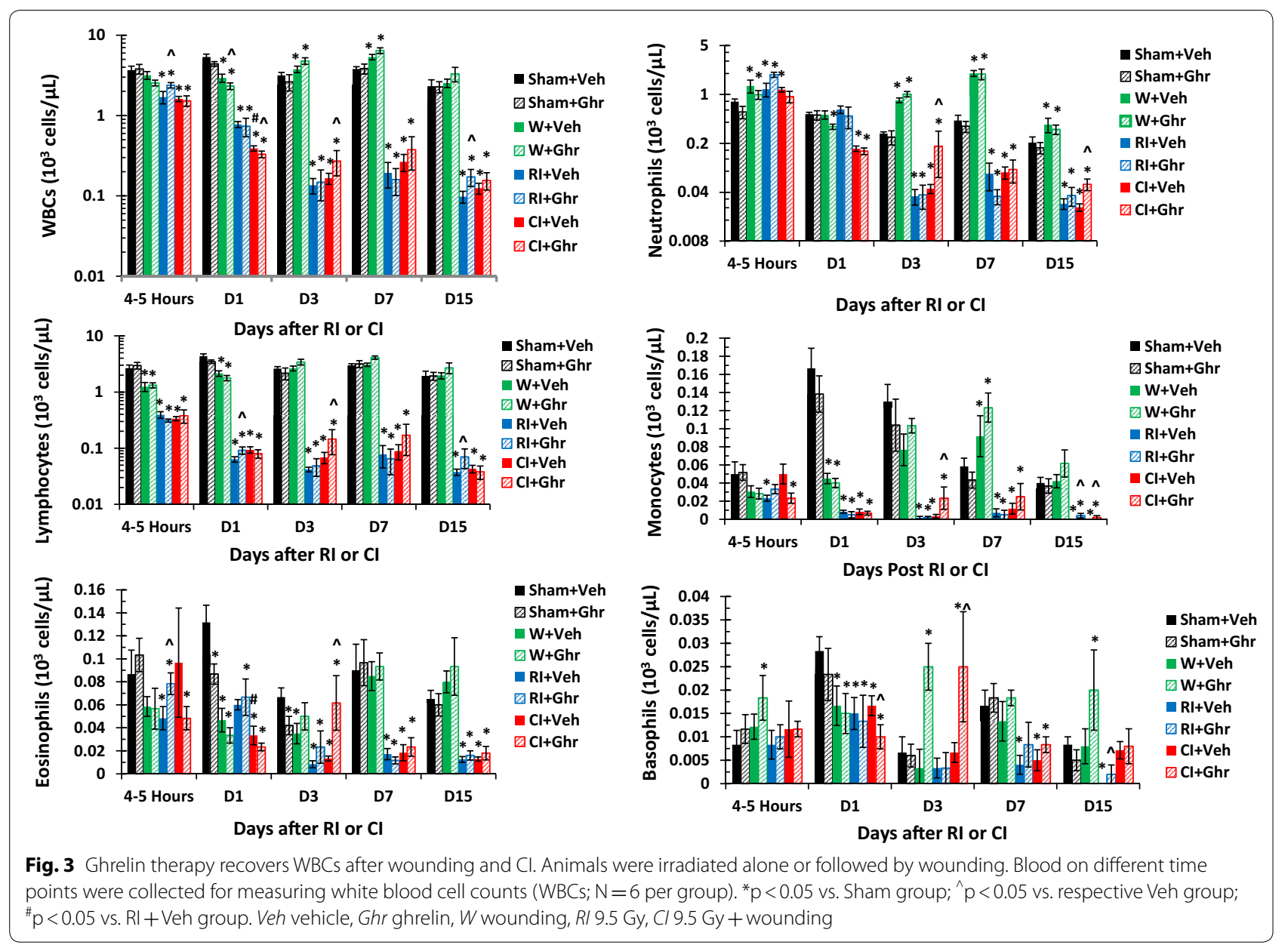

\section{Ghrelin therapy increases platelet counts after wounding and $\mathrm{Cl}$}

It is known that RI decreased platelets and CI further decreased them [5]. Figure 5 shows that RI-induced decreases in platelets began on day 7 and they continued to decrease on day 15. CI-induced enhancement was observed on days 7 and 15. Ghrelin therapy recovered platelet counts on days 7 and 15 . Wounding alone with ghrelin increased platelet counts on days 3, 7 and 15 .

\section{Ghrelin increases spleen weights after wounding and $\mathrm{Cl}$}

RI alone significantly decreases spleen weight in the beginning and then induces splenomegaly demonstrated only in surviving mice at 30 days [24]. In this study, RI began to decrease spleen weight within $4-5 \mathrm{~h}$, continued to decrease on day 1 to day 7 and then remained the nadir. CI enhanced the weight reduction only on day 1. Ghrelin therapy recovered the weight on day 1 and day 15 . Wounding alone with either vehicle or ghrelin significantly increased the weights on days 3,7 and 15 (Fig. 6).

\section{Ghrelin increases splenocytes after wounding and $\mathrm{Cl}$}

RI alone significantly decreases splenocyte counts within $4-5 \mathrm{~h}$ and continues to decrease on day 1 to day 3 then remained nadir on days 7 and 15 . CI enhanced the reduction of cell counts on days 1, 3 and 15. Ghrelin therapy recovered the cell counts on days 3 and 15 in CI mice. Ghrelin significantly increased the cell counts in sham mice and wounded mice on days 7 and 15 (Fig. 6).

\section{Ghrelin therapy enhances and sustains G-CSF increases after $\mathrm{Cl}$}

$\mathrm{RI}$ and CI have been shown to increase G-CSF and CI increases it more than RI [4]. As shown in Fig. 7, we found that wounding increased G-CSF at 4-5 h, days 1, 3 and 7, whereas ghrelin did not enhance the increases. $\mathrm{RI}$ increased G-CSF at 4-5 $\mathrm{h}$ but returned to the baseline on day 1 , then increased again on days 3,7 and 15 . Ghrelin diminished the RI-induced increases on day $15 . \mathrm{CI}$ enhanced its increases more than RI at $4-5 \mathrm{~h}$, days $1,3,7$ and 15. Ghrelin therapy further increased G-CSF on day 15. This ghrelin-enhanced increase was corresponded 

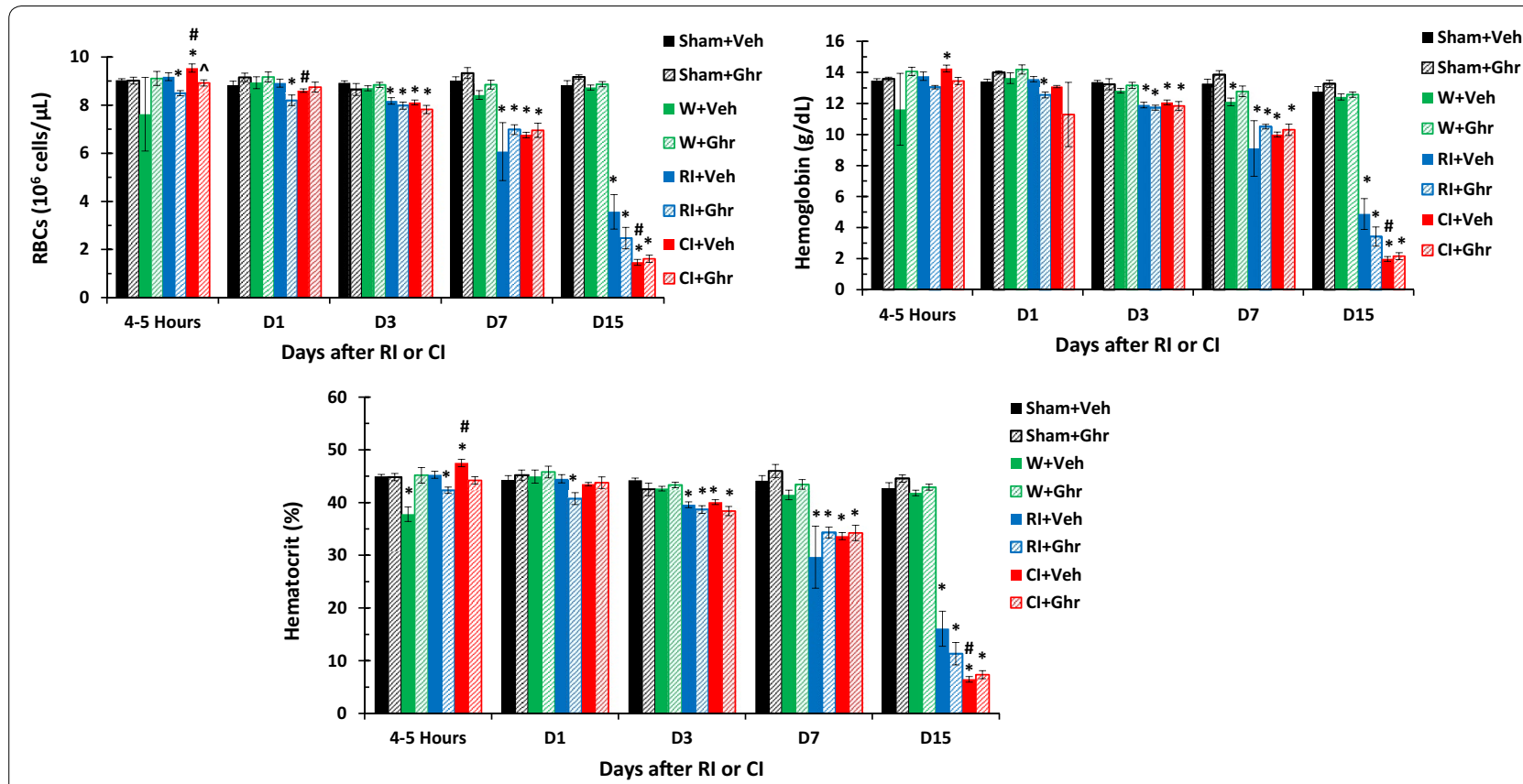

Fig. 4 Ghrelin therapy does not change RBCs after wounding, Rl or Cl. Animals were irradiated alone or followed by wounding. Blood on different time points were collected for measuring red blood cell counts (RBCs), hemoglobin levels, and hematocrit values ( $N=6$ per group). ${ }^{*} p<0.05$ vs. Sham group; ${ }^{*} \mathrm{p}<0.05$ vs. RI + Veh group. WBCs white blood cells, Veh vehicle, Ghr ghrelin, W wounding, R/ 9.5 Gy, Cl 9.5 Gy + wounding

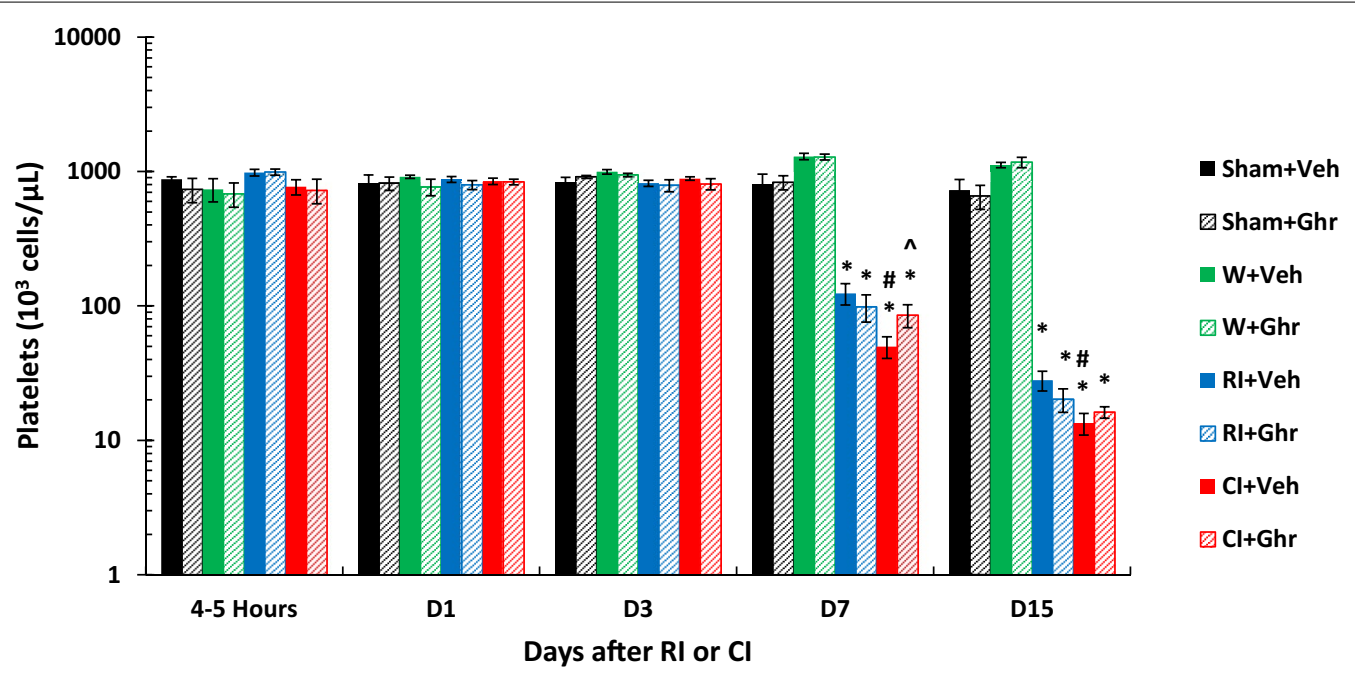

Fig. 5 Ghrelin therapy increases platelet counts after wounding and Cl. Animals were irradiated alone or followed by wounding. Blood on different time points were collected for measuring platelet counts ( $N=6$ per group). ${ }^{*} p<0.05$ vs. Sham group; ${ }^{\wedge} p<0.05$ vs. respective Veh group; ${ }^{\#} p<0.05$ vs. $\mathrm{RI}+$ Veh group. WBCs white blood cells, Veh vehicle, Ghr ghrelin, W wounding, Rl $9.5 \mathrm{~Gy}$, Cl 9.5 Gy + wounding

with the enhanced increase in spleen (Fig. 7b), ileum (Fig. 7c) and kidney (Fig. 7d) but not in bone marrow cells (Fig. 7e). Spleen, ileum, and kidney displayed CIenhanced increases in G-CSF while bone marrow exhibited no CI enhancement. The data on day 3 in spleen were presented, different from day 7 in other organs, because there were no changes in G-CSF on day 7.

\section{Ghrelin therapy enhances KC increases after $\mathrm{Cl}$}

$\mathrm{RI}$ and $\mathrm{CI}$ have been shown to increase $\mathrm{KC}$ and $\mathrm{CI}$ increases it more than RI [4]. As shown in Fig. 8, we found that wounding increased $\mathrm{KC}$ at $4-5 \mathrm{~h}$, days 1,3 , and 7 and returned to the baseline on day 15, whereas ghrelin inhibited the increase at $4-5 \mathrm{~h}$, but left $\mathrm{KC}$ alone on days 1 and 3 . RI increased $\mathrm{KC}$ at $4-5 \mathrm{~h}$. The 

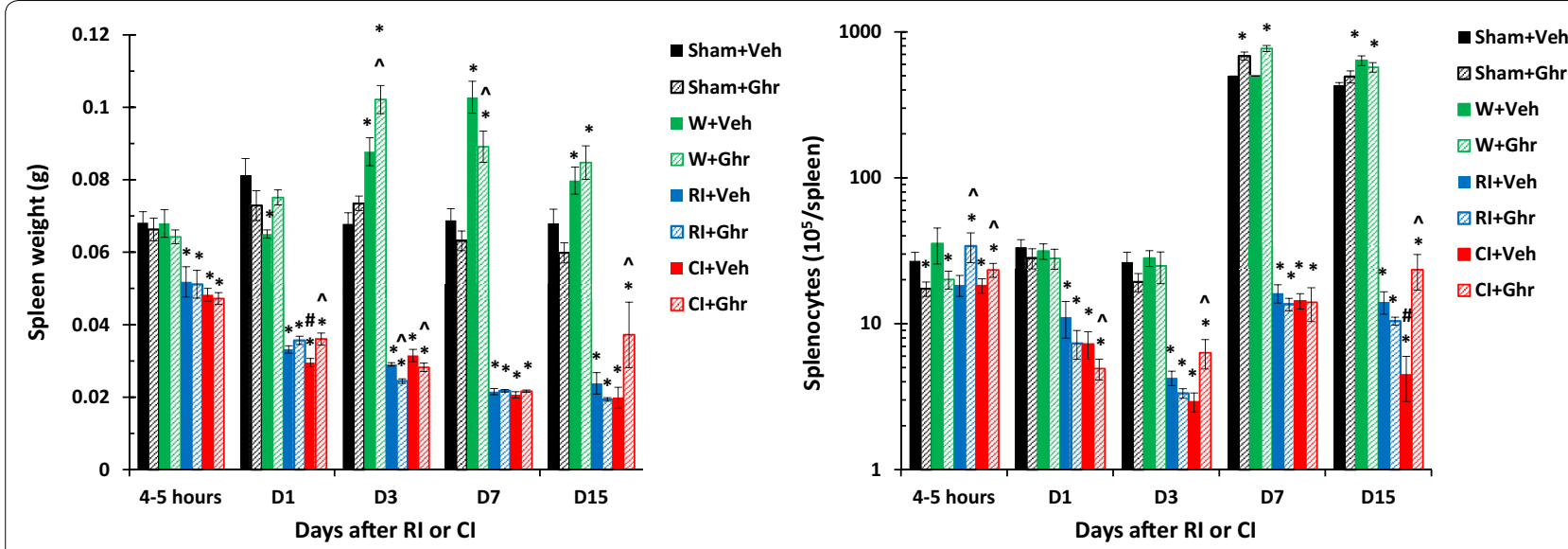

Fig. 6 Ghrelin increases spleen weights and splenocyte counts after wounding and Cl. Animals were irradiated alone or followed by wounding. Spleens on different time points were collected for measuring spleen weights and splenocyte counts ( $N=6$ per group). ${ }^{*} p<0.05 \mathrm{vs}$. Sham group; ${ }^{\wedge}<<0.05$ vs. respective Veh group; ${ }^{p} p<0.05$ vs. Rl + Veh group. WBCs white blood cells, Veh vehicle, Ghr ghrelin, $W$ wounding, $R / 9.5 \mathrm{~Gy}, \mathrm{Cl}$ $9.5 \mathrm{~Gy}+$ wounding

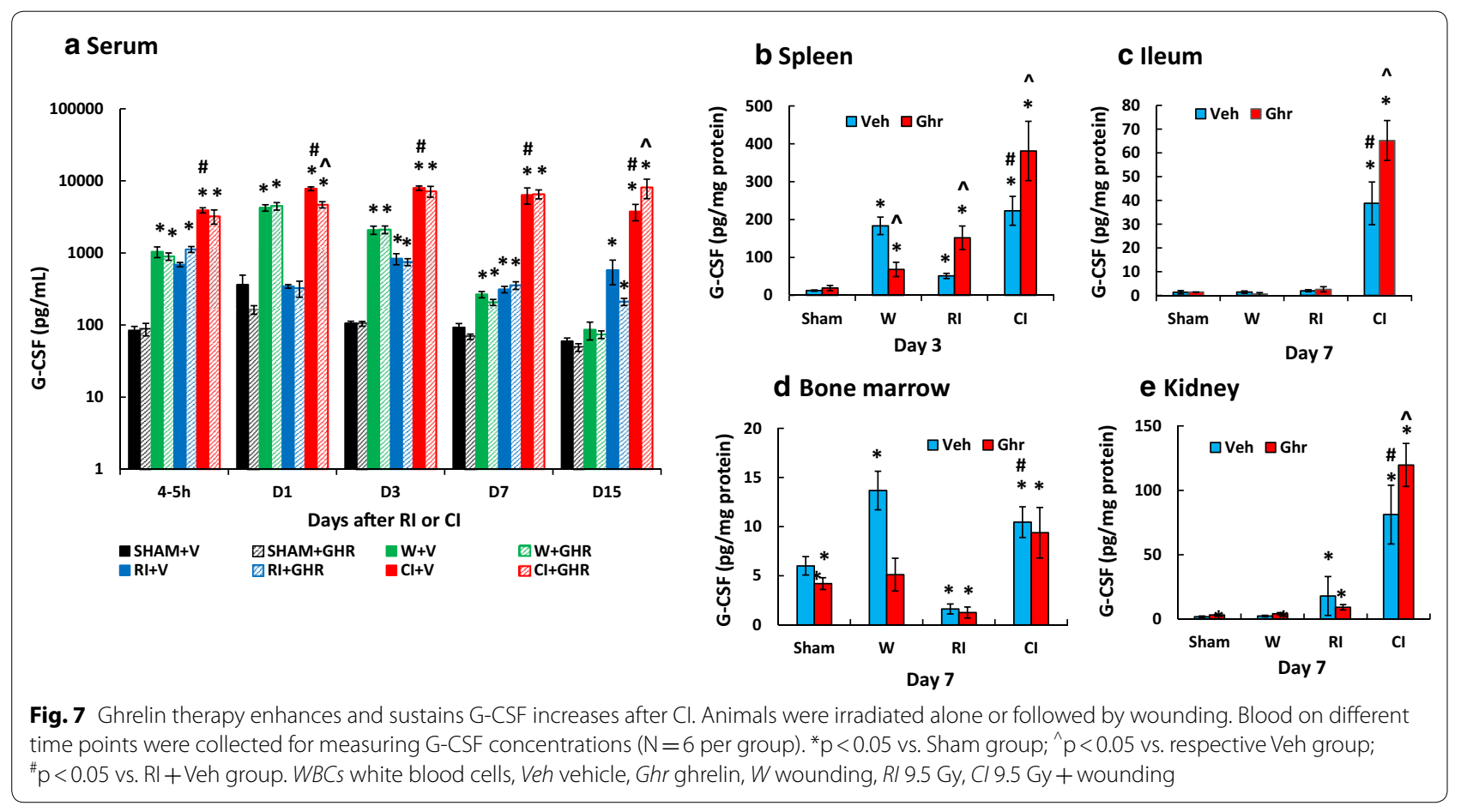

RI-induced KC increase was diminished on day 1 and 3 and returned to the baseline on day 7. Ghrelin therapy inhibited RI-induced KC increases on 4-5 h and day 1. CI further increased $\mathrm{KC}$ on $4-5 \mathrm{~h}$, days $1,3,7$, and 15. Ghrelin diminished the RI-induced increases on day 15. CI enhanced its increases more than RI at $4-5 \mathrm{~h}$, days 1 , 3, 7 and 15. Ghrelin therapy attenuated the $\mathrm{KC}$ increases at $4-5 \mathrm{~h}$ and day 1 , but enhanced the $\mathrm{KC}$ increase on day 15. This ghrelin-enhanced increase in blood was corresponded with the enhanced increase in $\mathrm{KC}$ found in kidney (Fig. 8d) but not in spleen (Fig. 8b), ileum (Fig. 8c) and bone marrow cells (Fig. 8e). Kidney displayed an enhanced increase in $\mathrm{KC}$ after $\mathrm{CI}$ while spleen, ileum and lung exhibited no $\mathrm{KC}$ enhancement by $\mathrm{CI}$. The data at day 


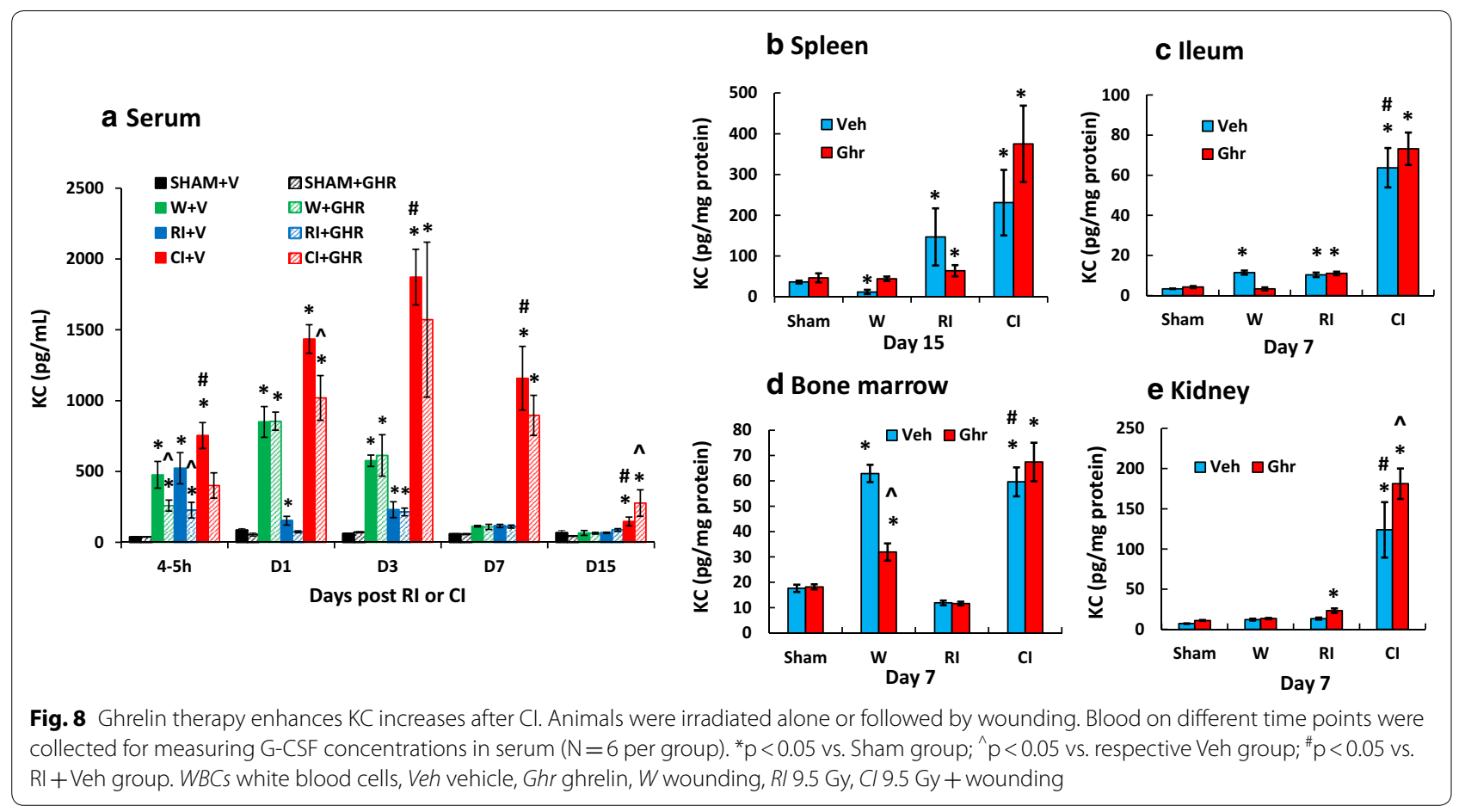

15 in spleen were presented, different from day 7 in other organs, because there were no changes in $\mathrm{KC}$ levels in spleen.

\section{Ghrelin therapy decreases caspase- 3 after $\mathrm{Cl}$}

CI increases caspase- 3 more than RI in ileum [39, 40]. In this study, we found significant decreases in caspase- 3 in the bone marrow of RI and CI animals from day 1 through day 15 . On day 3 , ghrelin therapy significantly decreased caspase-3 levels in RI mice on day 15 . In CI mice, ghrelin therapy significantly decreased caspase- 3 levels on day 3 and day 15. In sham and wounded animals, ghrelin did not affect caspase-3 baselines on day 3, but significantly diminished caspase-3 levels on day 15 (Fig. 9).

\section{Discussion}

Our novel results are the first to show that ghrelin therapy sustained G-CSF and KC increase in bone marrow and reduced bone marrow injury in $\mathrm{CI}$ mice. The amelioration of bone marrow injury began as early as day 1 and continued to sustain up to day 15 . Perhaps because that amelioration took place at day 1 in bone marrow, peripheral WBCs of all types were better recovered on day 3 , although only neutrophils and monocytes continued to increase on day 15.

Neutrophils are matured in bone marrow, resided and retained in the hematopoietic cords of bone marrow reserve, which is mediated by stromal cell-derived factor $(\mathrm{SDF}-1 \alpha)$ constitutively expressed in bone marrow.
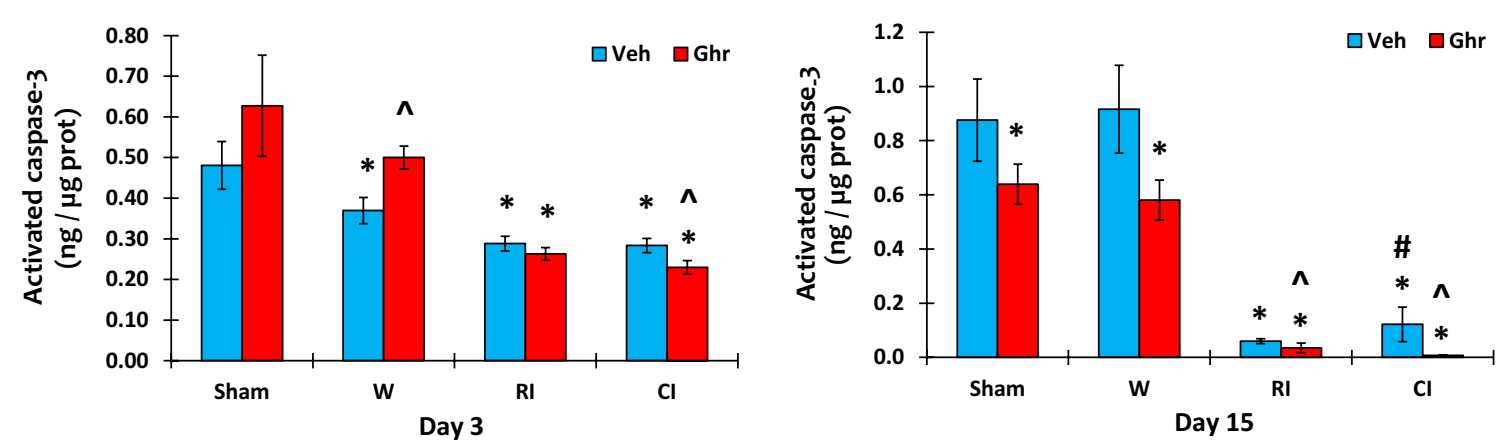

Fig. 9 Ghrelin therapy decreases caspase-3 after Cl. Animals were irradiated alone or followed by wounding. Blood on different time points were collected for measuring KC concentrations in serum ( $N=6$ per group). ${ }^{*} p<0.05$ vs. Sham group; ${ }^{\wedge}<0.05$ vs. respective Veh group; ${ }^{\#} p<0.05$ vs. $\mathrm{RI}+$ Veh group. WBCs white blood cells, Veh vehicle, Ghr ghrelin, W wounding, R/ $9.5 \mathrm{~Gy}$, Cl $9.5 \mathrm{~Gy}+$ wounding 
Neutrophils in bone marrow have chemokine receptor 4 (CXCR4) expressed on their surface. G-CSF treatment inhibits SDF-1 $\alpha$ [41] and CXCR4 [42, 43] expressions and mobilizes mature neutrophils into circulation. The senescent neutrophils become apoptotic neutrophils. The latter is removed by bone marrow macrophages and becomes degraded in liver and spleen. This action of macrophage destroying apoptotic neutrophils stimulates the G-CSF production in bone marrow. When neutrophils are being mobilized to circulation from bone marrow reserve, they need to cross the sinusoidal endothelium. The crossing process is regulated by G-CSF [44]. Normally, approximately $10^{11}$ neutrophils exit the bone marrow daily. However, their half-life in the blood is $6.5 \mathrm{~h}$ [see review, 45]. Under episodes of inflammation or infection, neutrophils quickly exit bone marrow and are recruited to the site through chemoattraction of $\mathrm{KC}$ and macrophage inflammatory protein-2 (MIP-2) within a matter of hours [46].

Ghrelin, a stomach-derived peptide, has a half-life of approximately $31 \mathrm{~min}$ in plasma [37, 38]. In this study, we found that ghrelin therapy sustained the circulating G-CSF increase, which was significantly contributed by ileum, spleen, kidney, bone marrow and perhaps other untested organs, stimulated myeloid progenitors in bone marrow for neutrophil proliferation and maturation. Then, G-CSF disrupted the retention signal delivered by SDF- $1 \alpha$ and facilitated the migration of neutrophils across the bone marrow sinusoidal endothelium in response to the chemotactic gradient created by blood chemokines such as KC. Neutrophil mobilization to circulation led to an increase in blood neutrophil counts that were observed and beneficial against systemic bacterial infection [4, Fig. 3], thereby, leading to increased animal survival.

RI and CI significantly reduce WBCs as previously reported [5, 7]. In the current study, by day 30 after RI or CI, surviving mice still displayed low values of WBCs, mainly neutrophils, lymphocytes, monocytes and eosinophils (Fig. 3). However, in CI mice, in addition to circulating neutrophil increases, ghrelin therapy increased other types of leukocytes, suggesting that ghrelin accelerates overall bone-marrow cell proliferation and maturation, as confirmed in Fig. 2. Ghrelin may have acted via GHSR-1 $\alpha$ (i.e., ghrelin receptors, coupling to G protein)mediated PI3K/Akt/eNOS/NO signal pathway [30] to initiate proliferation and differentiation of myeloid progenitors into mature granulocytes and induce hematopoietic stem-cell mobilization from the bone marrow into the bloodstream. On the other hand, because GHSR-1 $\alpha$ is expressed in lymphocytes [47], the action of ghrelin directly to preserve lymphocytes cannot be ruled out.
RI and CI significantly reduce RBCs, hemoglobin levels, and hematocrit values as previously reported, and CI reduces more than RI $[5,7]$. In the current study, the comparable results were found. On day 30 after RI or CI, surviving mice still displayed low values of RBCs (Fig. 4). Ghrelin did not mitigate RI or CI-induced decreases in RBC counts, hemoglobin levels, and hematocrit values. The results are inconsistent with the observation in mice exposed to radiation followed by burn [24]. Nevertheless, ghrelin treatment improved numbers of platelets in CI mice but not in RI-mice, a similar observation after radiation followed burn [24]. This ghrelin differential effects between RI and CI might suggest that this peptide also could stimulate megakaryocytes in the bone marrow (Fig. 1) under certain yet undefined conditions, like platelet recovery resulting from IL-12 treatment [48] and pegylated G-CSF [7]. From our results, we postulate that ghrelin passes the bone barrier and enters bone marrow to promote the thrombocytogenesis from megakaryocytes and releases platelets to peripheral blood to mitigate the platelet depletion in CI mice (Fig. 6), a previously unrecognized effect of ghrelin. This thrombocytogenesis may not be associated with thrombopoietin (TPO) because ghrelin therapy decreased TPO (data not shown).

We observed that RI and CI reduced spleen weights and splenocyte counts. Radiation is known to decrease $\mathrm{CD} 4+$ and $\mathrm{CD} 8+\mathrm{T}$ cells and increase CD4+ CD8+ T cells in the thymus and decreases CD4+ and CD8+ T cells in the spleen [48]. We found that ghrelin mitigated the CI-induced spleen weight loss and splenocyte loss on day 3 and day 5 (Fig. 6). Ghrelin might stimulate proliferation of splenic T cells [34]. It is reported [34] that ghrelin is expressed in $\mathrm{T}$ cells and exerts prothymic and anti-inflammatory effects. It is segregated within the lipid raft domains upon TCR ligation. Silencing ghrelin gene in primary human $\mathrm{T}$ cells activates $\mathrm{I} \mathrm{K} B$ and increases Th1 cytokines and IL-17 secretion [34]. Our dynamic cytokine profile in blood after RI and CI agrees with the observation in human cells (Kiang et al. unpublished data). Further studies to elucidate the mechanisms of CIinduced mitigation will be required to explain the different responses of RI and CI mice.

Caspase- 3 is a critical protease in caspase-dependent apoptosis $[49,50]$. It is increased in ileum after irradiation and combined injury [40]. In bone marrow, no increased activated caspase-3 levels were found, but RI and CI decreased caspase- 3 levels on day 3 and continue to decrease the levels on day 15. Ghrelin therapy significantly reduced its levels in all sham, wounded, RI, and CI animals for stopping apoptosis (Fig. 9). It is evident that caspase-independent necroptosis is another form of programed cell death that involves receptor-interacting 
protein kinase 1 (RIPK1) and RIPK3. RIPK1 activates RIPK3 [51]. Our preliminary data indicate that ghrelin reduces RIPK3 in bone marrow on day 3 after RI and $\mathrm{CI}$, suggesting presence of a RI and CI-induced RIPKinduced necroptosis. However, radiation-mediated crosstalk among apoptosis, necroptosis, and pyroptosis exists in immune cells. Therefore, pyroptosis in bone marrow cannot be ruled out and should be explored.

Ghrelin is found to reduce Bax (a pro-apoptotic protein) and increase Bcl-2 (an anti-apoptotic protein) in a chronic liver injury model [28]. Determining the differential activities of ghrelin on Bax and Bcl-2 in bone marrow of RI and CI mice would be informative, considering that mice in these models of acute injuries do not have chronic liver disease.

Ghrelin has been demonstrated as a countermeasure against radiation combined with sepsis [14]. It is suggested the effect is based on complex neurogenic effects of this peptide, involving with activation of cholinergic pathway, inhibition of sympathetic nervous system (SNS) and down-regulation of proinflammatory cytokines [5254]. Therefore, ghrelin's beneficial effects following irradiation combined with sepsis may have been correlated with the rebalance of the dysregulated sympathetic and parasympathetic (PNS) nervous systems [52]. It is possible that ghrelin-induced improvement of survival in our CI model is mediated by the rebalance of cytokines, SNS and PNS. This hypothesis requires confirmation.

We found that ghrelin sustained G-CSF and KC levels in bone marrow and circulatory blood (Figs. 7, 8), which promoted neutrophil proliferation, maturation and mobilization from bone marrow to circulation and injured areas. This unique feature makes ghrelin a better candidate than other G-CSF stimulators such as Toll-like receptor 2 agonists [55]. The latter induces side effects including appetite loss and edema [55]. Ghrelin administration accelerates body weight recovery and is found no edema [31].

In summary, skin wounds enhanced the RI-induced bone marrow injury as indicated by increases in adipocyte counts and decreases in megakaryocyte counts that were reversed by ghrelin therapy and confirmed by increased bone marrow cell counts. In CI mice, ghrelin therapy significantly recovered circulating WBCs and platelet counts but not RBCs. The recovery of neutrophil counts was mediated by sustained increases in G-CSF and $\mathrm{KC}$ in serum and spleen, ileum, lung, and kidney. In bone marrow, ghrelin therapy reduced activated caspase-3 levels after $\mathrm{CI}$, suggesting cell recovery. In spleen, ghrelin therapy mitigated CI-induced spleen weight and splenocyte losses and CI-induced enhancement of G-CSF and $\mathrm{KC}$ increases. These results demonstrate efficacy of ghrelin as a radio-mitigator/therapy agent for $\mathrm{CI}$.

\section{Abbreviations}

AFRRI: Armed Forces Radiobiology Research Institute; Cl: combined injury; G-CSF: granulocyte-colony stimulating factor; GHSR: growth hormone secretagogue receptor; i.v: intravenous; KC: keratinocyte chemoattractant; p.o.: per os; RBCs: red blood cells; RCl: radiation combined injury; Rl: radiation injury; S.c. subcutaneous; TBSA: total body surface area; VSD: Veterinary Science Department; W: wound; WBCs: white blood cells.

\section{Authors' contributions}

JGK conceived and designed the experiments in the manuscript. JGK, MNA, and JTS performed the experiments. JGK and JTS analyzed data and plotted the graphs for figures. JGK wrote the manuscript. All authors read and approved the final manuscript.

\section{Author details \\ ${ }^{1}$ Radiation Combined Injury Program, Armed Forces Radiobiology Research Institute, Bethesda, MD 20889, USA. ${ }^{2}$ Department of Pharmacology and Molecular Therapeutics, Uniformed Services University of the Health Sciences, Bethesda, MD 20814, USA. ${ }^{3}$ Department of Medicine, Uniformed Services University of the Health Sciences, Bethesda, MD 20814, USA.}

\section{Acknowledgements}

The authors gratefully acknowledge the Veterinary Sciences Department staff for animal care and complete blood counts and histology slides, Dr. Vitaly Nagy and Radiation Dosimetry staff for conducting whole-body irradiation. Research was supported by NIH/NIAID YI-AI-5045-04 to JGK and AFRRI RAB32164 and RAB33529 to JGK.

\section{Competing interests}

The authors declare that they have no competing interests.

\section{Availability of data and materials}

All relevant data are within this published paper.

\section{Ethics approval and consent to participate}

The animal experiment was approved by the AFRRI IACUC. The IACUC protocol number was 2013-12-015 with Biosample Sharing Request Approval to JGK.

\section{Disclaimer}

The views, opinions, and findings contained in this report are those of the authors and do not reflect official policy or positions of the Armed Forces Radiobiology Research Institute, the Uniformed Services University of the Health Sciences, the National Institute of Allergy and Infectious Diseases, the Department of Defense, or the United States government. The commercial products identified in this manuscript do not imply recommendation or endorsement by the federal government and do not imply that the products identified are necessarily the best available for the purpose.

\section{Publisher's Note}

Springer Nature remains neutral with regard to jurisdictional claims in published maps and institutional affiliations.

Received: 25 January 2018 Accepted: 30 March 2018

Published online: 05 April 2018

\section{References}

1. lijima S. Pathology of atomic bomb casualties. Acta Pathol Jpn. 1982;32(Suppl. 2):237-70.

2. Kishi HS. Effects of the "special bomb": recollection of a neurosurgeon in Hiroshima. Neurosurgery. 2000;47:441-6.

3. Barabanova AV. Significance of beta-radiation skin burns in Chernobyl patients for the theory and practice of radiopathology. Vojnosanit Pregl. 2006;63:477-80.

4. Kiang JG, Jiao W, Cary LH, Mog SR, Elliott TB, Pellmar TC, Ledney GD. Wound trauma increases radiation-induced mortality by increasing 
iNOS, cytokine concentrations, and bacterial infections. Radiat Res. 2010;173:319-32.

5. Kiang JG, Garrison BR, Burns TM, Zhai M, Dews IC, Ney PH, Fukumoto R, Cary LH, Elliott TB, Ledney GD. Wound trauma alters ionizing radiation dose assessment. Cell Biosci. 2012;2:20.

6. Kiang JG, Ledney GD. Skin injuries reduce survival and modulate corticosterone, C-reactive protein, complement component 3, IgM, and prostaglandin E2 after whole-body reactor-produced mixed field ( $n+-$ photons) irradiation. Oxid Med Cell Longev. 2013;2013:821541.

7. Kiang JG, Zhai M, Liao P-J, Bolduc DL, Elliott TB, Gorbunov NV. Pegylated G-CSF inhibits blood cell depletion, increases platelets, blocks splenomegaly, and improves survival after whole-body ionizing irradiation but not after irradiation combined with burn. Oxid Med Cell Longev. 2014;2014:481392.

8. Kiang JG, Fukumoto R. Ciprofloxacin increases survival after ionizing irradiation combined injury: $\gamma-\mathrm{H} 2 \mathrm{AX}$ formation, cytokine/chemokine, and red blood cells. Health Phys. 2014;106:720-6.

9. Ledney GD, Elliott TB. Combined injury: factors with potential to impact radiation dose assessments. Health Phys. 2010;98:145-52.

10. Ledney GD, Elliott TB, Moore MM. Modulations of mortality by tissue trauma and sepsis in mice after radiation injury. In: Mossman KL, Mills WA, editors. The biological basis of radiation protection practice. Baltimore: Williams and Wilkins; 1992. p. 202-17.

11. Ledney GD, Stewart DA, Exum ED, Sheehy PA. Skin wound-enhanced survival and myelocytopoiesis in mice after whole-body irradiation. Acta Radiol Oncol. 1981;20:29-38.

12. Palmer JL, Deburghgraeve CR, Bird MD, Hauer-Jensen M, Kovacs EJ. Development of a combined radiation and burn injury model. J Burn Care Res. 2011;32:317-23.

13. Alpen EL, Sheline GE. The combined effects of thermal burns and whole-body X-radiation on survival time and mortality. Ann Surg. 1954;140:113-8.

14. Shah KG, Wu R, Jacob A, Blau SA, Ji Y, Dong W, Marini CP, Ravikumar TS, Coppa GF, Wang P. Human ghrelin ameliorates organ injury and improves survival after radiation injury combined with severe sepsis. Mol Med. 2009; 15:407-14.

15. Valeriote FA, Baker DG. The combined effects of thermal trauma and x-irradiation on early mortality. Radiat Res. 1964;22:693-702.

16. Korlof B. Infection of burns, I. A bacteriological and clinical study of 99 cases. II. Animal experiments: burns and total body $x$-irradiation. Acta Chiropractic Scandinavian. 1956;209(Supplement):1-144.

17. Brooks JW, Evans El, Ham WT Jr, Reid JD. The influence of external body radiation on mortality from thermal burns. Ann Surg. 1952;136:533-45.

18. Reid JD, Brooks JW, Ham WT, Evans El. The influence of X-radiation on mortality following thermal flash burns: the site of tissue injury as a factor determining the type of invading bacteria. Ann Surg. 1955;142:844-50.

19. Baxter H, Drummond JA, Stephens-Newsham LG, Randall RG. Studies on acute total body irradiation in animals. I. Effect of streptomycin following exposure to a thermal burn and irradiation. Plastic Reconstruction Surg. 1953;12:439-45.

20. Fukumoto R, Burns TM, Kiang JG. Ciprofloxacin enhances stress erythropoiesis in spleen and increases survival after whole-body irradiation combined with skin-wound Trauma. PLoS ONE. 2014;9:e90448.

21. Lausevic Z, Lausevic M, Trbojevic-Stankovic J, Krstic S, Stojimovic B. Predicting multiple organ failure in patients with severe trauma. Can J Surg. 2008:51:97-102.

22. Zou Z, Sun H, Su Y, Cheng T, Luo C. Progress in research on radiation combined injury in China. Radiat Res. 2008;169:722-9.

23. Kiang JG, Gorbunov NV. Bone marrow mesenchymal stem cells increases survival after ionizing irradiation combined with wound trauma: characterization and therapy. J Cell Sci Ther. 2014;5:190.

24. Kiang JG, Zhai M, Liao P-J, Elliott TB, Gorbunov NV. Ghrelin therapy improves survival after whole-body ionizing irradiation combined with wound or burn: amelioration of leukocytopenia, thrombopenia, splenomegaly, and bone marrow injury. Oxid Med Cell Longev. 2014;2014:215858.

25. Kojima M, Hosoda H, Date Y, Nakazato M, Matsuo H, Kangawa K. Ghrelin is a growth-hormone-releasing acylated peptide from stomach. Nature. 1999;402:656-60.
26. Inui A, Asakawa A, Bowers CY, Mantovani G, Laviano A, Meguid MM, Fujimiya M. Ghrelin, appetite, and gastric motility: the emerging role of the stomach as an endocrine organ. FASEB J. 2004;18:439-56.

27. Baatar D, Patel K, Taub DD. The effects of ghrelin on inflammation and the immune system. Mol Cell Endocrinol. 2011;340:44-58.

28. Kabil NN, Seddiek HA, Yassin NA, Gamal-Eldin MM. Effect of ghrelin on chronic liver injury and fibrogenesis in male rats: possible role of nitric oxide. Peptides. 2014;52:90-7.

29. Xu X, Jhun BS, Ha CH, Jin ZG. Molecular mechanisms of ghrelinmediated endothelial nitric oxide synthase activation. Endocrinol. 2008;149:4183-92.

30. Chen X, Chen Q, Wang L, Li G. Ghrelin induces cell migration through GHSR1a-mediated PI3K/Akt/eNOS/NO signaling pathway in endothelial progenitor cells. Metabolism. 2012;62:743-52.

31. Gorbunov NV, Kiang JG. Ghrelin therapy decreases incidents of intracranial hemorrhage in mice after whole-body ionizing irradiation combined with burn trauma. Int J Mol Sci. 2017;18:E1693.

32. Peng Z, Zhu Y, Zhang Y, Wilhelmsen $K$, Jia C, Jin J, Xue Q, Feng X, Zhang F, Yu B. Effects of ghrelin on pulmonary NOD2 mRNA expression and NF-KB activation when protects against acute lung injury in rats challenged with cecal ligation and puncture. Int Immunopharmacol. 2012;13:440-5.

33. Ogura Y, Inohara N, Benito A, Chen FF, Yamaoka S, Nunez G. Nod2, a Nod1/Apaf-1 family member that is restricted to monocytes and activates NF-kappaB. J Biol Chem. 2001;276:4812-48.

34. Dixit VD, Yang H, Cooper-Jenkins A, Giri BB, Patel K, Taub DD. Reduction of T cell-derived ghrelin enhances proinflammatory cytokine expression: implications for age-associated increases in inflammation. Blood. 2009;113:5202-5.

35. Montgomery CA. Oncologic and toxicologic research: alleviation and control of pain and distress in laboratory animals. Cancer Bull. 1990:42:230-7.

36. Tomasivic SP, Coghlan LG, Gray KN, Mastromarino AJ, Travis EL. IACUC evaluation of experiments requiring death as an end point: a cancer center's recommendations. Lab Animal. 1988;17:31-4.

37. International Standardization Organization and ASTM International. Standard practice for use of an alanine-EPR dosimetry system. ISO/ASTM international standard 51607-2013(E). Geneva: ISO and West Conshohocken (US:PA): ASTM International; 2013. p. 7.

38. Kiang JG, Smith JT, Anderson MN, Swift JM, Gupta P, Balakathiresan N, Maheshwari RK. Hemorrhage exacerbates radiation effects on survival, leukocytopenia, thrombopenia, erythropenia, bone marrow cell depletion and hematopoiesis, and inflammation-associated microRNAs expression in kidney. PLoS ONE. 2015;10:e0139271.

39. Kiang JG, Garrison BR, Gorbunov NV. Radiation combined injury: DNA damage, apoptosis, and autophagy. Adapt Med. 2010;2:1-10.

40. Kiang JG, Smith JT, Anderson MN, Elliott TB, Gupta P, Balakathiresan N, Maheshwari RK, Knollmann-Ritschel B. Hemorrhage enhances cytokine, complement component 3, and caspase-3, and regulates microRNAs associated with intestinal damage after whole-body gamma-irradiation in combined injury. PLoS ONE. 2017;12:e0184393.

41. Semerad CL, Liu F, Gregory AD. StumpfK, Link DC. G-CSF is an essential regulator of neutrophil trafficking from the bone marrow to the blood. Immunity. 2002;17:413-23.

42. De La Luz SM, Gasperini P, McCormick PJ, Zhu J, Tosato G. Transcription factor Gfi-1 induced by G-CSF is a negative regulator of CXCR4 in myeloid cells. Blood. 2007;110:2276-85.

43. Kim HK, De La Luz SM, Williams CK, Gulino AV, Tosato G. G-CSF downregulation of CXCR4 expression identified as a mechanism for mobilization of myeloid cells. Blood. 2006;108:812-20.

44. Demetri GD, Griffin JD. Granulocyte colony-stimulating factor and its receptor. Blood. 1991;78:2791-808.

45. Furze RC, Rankin SM. Neutrophil mobilization and clearance in the bone marrow. Immunology. 2008;135:281-8.

46. Furze RC, Rankin SM. The role of the bone marrow in neutrophil clearance under homeostatic conditions in the mouse. FASEB J. 2008;22:3111-9.

47. Youm YH, Yang H, Sun Y, Smith RG, Manley NR, Vandanmagsar B, Dixit VD. Deficient ghrelin receptor-mediated signaling compromises thymic stromal cell microenvironment by accelerating thymic adiposity. J Biol Chem. 2009;284:7068-77. 
48. Li H, Cui W, Hull L, Smith JT, Kiang JG, Xiao M. Effect of low-moderate doses of $Y$-radiation on mouse hematopoietic and immune system. Radiat Res. 2018 (in review).

49. Kiang JG. Exacerbation of mild hypoxia on acute radiation syndrome and subsequent mortality. Adaptive Med. 2017;9:28-33.

50. Huang CY, Yu LC. Pathophysiological mechanisms of death resistance in colorectal carcinoma. World J Gatroenterol. 2015;7:11777-92.

51. Cook WD, Moujalled DM, Ralph TJ, Lock P, Young SN, Murphy JM, Vaus DL. RIPK1- and RIPK3-induced cell death mode is determined by target availability. Cell Death Diff. 2014;21:1600-21.

52. Jacob A, Shah KG, Wu R, Wang P. Ghrelin as a novel therapy for radiation combined injury. Mol Med. 2010;16:137-243.
53. Cheyuo C, Wu R, Zhou M, Jacob A, Coppa G, Wang P. Ghrelin suppresses inflammation and neuronal nitric oxide synthase in focal cerebral ischemia via the vagus nerve. Shock. 2011;35:258-65.

54. Stoyanova II. Ghrelin: expression and functions in the central nervous system. In: Ghrelin: production, action mechanisms and physiological effects. New York: Nova Science Publishers, Inc; 2011. p. 57-75. ISBN 978-1-61942-400-5.

55. Laping NJ, DeMartino MP, Cottom JE, Axten JM, Emery JG, Guss JH, Burman M, Foley JJ, Cheung M, Oliff A, Kumar S. TLR2 agonism reverses chemotherapy-induced neutropenia in Macaca fascicularis. Blood Adv. 2017;1:2553-62.
Ready to submit your research? Choose BMC and benefit from:

- fast, convenient online submission

- thorough peer review by experienced researchers in your field

- rapid publication on acceptance

- support for research data, including large and complex data types

- gold Open Access which fosters wider collaboration and increased citations

- maximum visibility for your research: over $100 \mathrm{M}$ website views per year

At BMC, research is always in progress.

Learn more biomedcentral.com/submissions 